\title{
ITS-2 rDNA Nemabiome Metabarcoding in two Isolated Populations of Wild Roe Deer (Capreolus Capreolus) Reveals Variation in Gastrointestinal Nematode Community Composition Between Regions and Among Age Classes
}

Camille Beaumelle ( $\nabla$ camille.beaumelle@univ-smb.fr)

Lyon 1 University: Universite Claude Bernard Lyon 1

\section{Libby Redman}

University of Calgary

jill de Rijke

University of Calgary

Janneke Wit

University of Calgary

Slimania Benabed

Lyon 1 University: Universite Claude Bernard Lyon 1

François Debias

Lyon 1 University: Universite Claude Bernard Lyon 1 Jeanne Duhayer

Lyon 1 University: Universite Claude Bernard Lyon 1

\section{Sylvia Pardonnet}

Lyon 1 University: Universite Claude Bernard Lyon 1

\section{Marie-Thérèse Poirel}

Lyon 1 University: Universite Claude Bernard Lyon 1

\section{Gilles Capron}

Office français de la biodiversité: Office francais de la biodiversite

\section{Stéphane Chabot}

Office français de la biodiversité: Office francais de la biodiversite

\section{Benjamin Rey}

Lyon 1 University: Universite Claude Bernard Lyon 1

\section{Glenn Yannic}

Savoie University: Universite Savoie Mont-Blanc

John Gilleard

University of Calgary 


\section{Gilles Bourgoin}

Lyon 1 University: Universite Claude Bernard Lyon 1

\section{Research Article}

Keywords: Strongyle, ungulate, parasitism, ASV, Haemoncus contortus, wildlife, diversity index

Posted Date: July 28th, 2021

DOI: https://doi.org/10.21203/rs.3.rs-744878/v1

License: (c) (1) This work is licensed under a Creative Commons Attribution 4.0 International License. Read Full License 


\section{Abstract}

\section{Background}

Gastrointestinal nematodes are ubiquitous for both domestic and wild ungulates which have varying consequences to health and fitness. They exist as complex communities of multiple co-infecting species and we have a very limited understanding of how these communities vary in different hosts, regions and circumstances or on how this affects their impacts.

\section{Methods}

We have undertaken ITS-2 rDNA nemabiome metabarcoding on populations of nematode larvae isolated from fecal samples of roe deer of different sex and age classes in the two isolated populations of Chizé and Trois Fontaines in France not co-grazing with any domestic ungulate species.

\section{Results}

We identified 100 Amplified Sequence Variants (ASVs) that assigned to 14 gastrointestinal nematode taxa overall either at genus (38\%), or species (62\%) level. These taxa were dominated by parasites classically found in cervids - e.g., Ostertagia leptospicularis, Spiculopteragia spp. Higher parasite species diversity was present in the Trois Fontaine than in the Chize populations including the presence of some species more typically seen in domestic livestock, (Haemonchus contortus, Bunostomum trigonocephalum, Cooperia punctata, Teladorsagia circumcincta). No differences in parasite species diversity or community composition was seen in the samples collected from three zones of differing habitat quality within the Chize region. Young roe deer hosted the highest diversity of gastrointestinal nematodes, with more pronounced effects of age apparent in Trois Fontaines. The effect of host age differed between gastrointestinal nematode species, e.g. there was little effect on Ostertagia leptospicularis but a high effect on Trichostrongylus spp. No effect of host sex was detected in either site.

\section{Conclusions}

The presence of some livestock parasite species in the Trois Fontaine roe deer popualtions was surprising given the isolation of this population away from grazing domestic livestock. However, it should be noted that a small group of sheep were resident in the region, albeit separately fenced, which raises some interesting questions regarding the introduction of non-native parasite species into wildlife populations. Overall, our results suggest complex interactions between hosts, environments and parasites and illustrate the power of the nemabiome metabarcoding approach to elucidate the composition of gastrointestinal nematode communities in wildlife.

\section{Background}

Gastrointestinal nematode parasites of wildlife and livestock have a worldwide distribution and have major ecological, economic and animal welfare impacts [1-3]. Gastrointestinal nematodes of wildlife can 
have negative impacts on the health and individual fitness of hosts [4] as well as on their population dynamics [5] which, in extreme cases, can ultimately lead to population extinction [6]. Consequently, understanding host-parasite relationships is important for sustainable wildlife management and determining parasite diversity and abundance is a crucial and challenging aspect $[7,8]$.

Multiple gastrointestinal nematode species often co-infect a single host. These species differ in their pathogenicity, even when closely phylogenetically related, and may have synergistic or antagonistic interactions [9-12]. The host immunological response to a parasitic infection can incur an important cost to host resources and has to be balanced with other energy demanding functions $[4,13]$. Therefore, the physiological and behavioral attributes of individual hosts influences infection level, parasite community composition and their effects $[14,15]$. The age, sex and reproductive status of hosts are important factors in this context, and determine the parasite community structure, i.e., abundance and diversity of parasites.

As their immune system is still immature, the highest abundance and diversity of parasites are generally observed in young individuals, (e.g. roe deer, Capreolus capreolus [16], Dall's sheep, Ovis dalli dalli [17], feral sheep, Ovis aries $[3,18])$. Similary, because of the deterioration of their immune system, senescent individuals usually host a higher abundance and diversity of parasites than adult individuals $[19,20]$. Variation in parasite abundance and diversity is also observed between sexes, and is generally higher in males [21]. The higher susceptibility of males to infection is usually related to the immunosuppressive effects of sex steroid hormones in males [22], sexual size dimorphism [23], and also to increased likehood of pathogen exposure [24].

Investigating parasite diversity in wildlife can be challenging [25]. Recently, next-generation sequencing metabarcoding approaches have been developed to investigate gastrointestinal nematode communities $[25,26]$. Metabarcoding allows the study of endoparasite communities, without prior assumption of which gastrointestinal nematode species are likely to be present. It also allows large numbers of samples to be processed simulatenously and can be highly sensitive allowing the detection of rare species [27]. Metabarcoding does not quantify the absolute number of parasites in a sample, but provides information on the proportions of each parasite species.

The aim of this study was to investigate the specific gastrointestinal nematode communities present in natural populations of the roe deer (Capreolus capreolus), a common and widely distributed ungulate species in Europe, as a case study. We used ITS-2 rDNA metabarcoding to determine the community composition of nematodes found in roe deer from two French populations inhabiting forests of contrasting quality of habitat. As the two populations of roe deer have been spatially isolated in fenced areas for more than 60 years, preventing cross-contamination with other ungulates (wild or domestic), we expected dominant species of nematode to be roe deer-specific parasites $(\mathrm{H} 1)$. We also expected sex and age to influence the community of gastrointestinal nematodes. More precisely, we expected to observe a higher parasitic diversity in young individuals of a few months of age than in adults ( $\mathrm{H} 2)$, and in males than in females $(\mathrm{H} 3)$, within both sites. Quality of habitat can influence the immune responses of hosts to 
parasites [28]. The sites of Trois Fontaines (northeastern France) and Chizé (Western France) have different environmental conditions (e.g., habitat and climate, see below), respectively characterized by a rich homogenous environment or a heterogeneous poor environment. It leads to lower physiological parameters in Chizé and different strategies of immune response in parasitized roe deer of the two populations $[28,29]$. In addition, gastrointestinal nematode communities and their abundance depends on meterological conditions and geographical region [30-32]. Consequently, we predicted we would observe differences of nemabiome in Chizé and Trois Fontaines with a higher diversity of gastrointestinal nematodes in roe deer living in Chizé, as well as among individuals living in the different sectors of Chizé [33], with a higher diversity in the sector with the poorest environment $(\mathrm{H} 4)$.

\section{Materials And Methods}

\section{Study areas}

The two study sites, Chizé and Trois Fontaines, are located in Western $\left(46^{\circ} 05^{\prime} \mathrm{N}, 0^{\circ} 25^{\prime} \mathrm{W}\right)$ and NorthEastern France $\left(48^{\circ} 43^{\prime} \mathrm{N}, 2^{\circ} 61^{\prime} \mathrm{W}\right)$, respectively. Both sites are fenced forests of 2,614 ha in Chizé and 1,360 ha in Trois Fontaines, preventing roe deer and other ungulates to move from or to the study sites. No other ungulates other than roe deer are present within the two sites, except wild boar. The two sites have different climate, soil and forest attributes. The oceanic climate in Chizé is characterized by mild winters and dry summers in contrast to Trois Fontaines where the continental climate results in rainy warm summers and cold winters. In both sites, forests are dominated by oak (Quercus sp.), beech (Fagus sylvatica) and hornbeam (Carpinus betulus), but with a more heterogeneous spatial distribution of species and coppice abundance and quality in Chizé [33] compared to Trois Fontaines. With its low productive forest, Chizé is considered a poor habitat for roe deer, in contrast to the highly productive forest of Trois Fontaines [34]. Consequently, in Trois Fontaines, the population of roe deer is increasing but keeping stable by yearly removals, whereas the population is stable in Chizé [28].

\section{Roe deer data}

Roe deer of known age are captured annually as part of a long-term monitoring program. Details of the capture procedure are available in Gaillard et al. [35]. Fecal samples were collected rectally in immobilized roe deer captured between January and March in 2018 and 2019 under a protocol approved by the Director of Food, Agriculture and Forest (Prefectoral order 2009-14 from Paris) and under authority of the Office Français de la Biodiversité. For each individual, we recorded the sex and age as well as the approximate location of capture. We also verified that individuals of different age and sex are equally distributed throughout the capture period and spatial localization (data not shown).

\section{Parasitological analyses and culture}

Fecal samples reached the parasitology laboratory of VetAgro Sup (Lyon, France) within 24h-48h after collection. On receipt, we set up coprocultures with feces mixed with vermiculite. After an incubation period of $10-12$ days at $24^{\circ} \mathrm{C}$ with regular mixing and moisture, the larvae were collected with a 
Baermann apparatus after $24 \mathrm{~h}$ of sedimentation in water. After determining the total number of L3 collected by counting an aliquot, we stored them in $70 \%$ ethanol until DNA extraction.

We also counted eggs of gastrointestinal nematodes following a modified McMaster protocol [36], with a solution of $\mathrm{ZnSO}_{4}$ (density = 1.36) and a McMaster slide, providing a theoretical sensitivity of 15 eggs per gram (epg) of feces. We also prepared a "control slide" to improve sensitivity of the technique by fully filling a $14 \mathrm{ml}$ tube with the remaining solution and covering it with a coverslip. After centrifugation (5 min at $1200 \mathrm{rpm}$ ), the coverslip was transferred on a microscope slide before microscopical observation. We attributed the value $7.5 \mathrm{epg}$ for parasite species detected on the control slide but not on the McMaster slide. Coproscopic data was reported only for samples containing enough L3 collected from coproculture and analyzed by metabarcoding.

\section{DNA extraction and metabarcoding}

DNA extraction was performed using the Qiagen DNeasy ${ }^{\circledR}$ powerSoil kit (Qiagen, Hilden, Germany) following manufacturer's instructions with an elution of $50-150 \mu \mathrm{l}$ and stored at $-20^{\circ} \mathrm{C}$ until analysis. ITS2 rDNA metabarcoding was performed using the protocol described by Avramenko et al. [26]. Briefly, the rDNA ITS-2 target was PCR-amplified from a 1:10 dilution of genomic DNA template. Negative experimental controls were included consisting of water in the PCR reaction instead of template DNA. These controls were handled in exactly the same way as the actual samples. All samples $(n=149)$ and negative controls ( $n=22)$ were tagged with unique identifers to allow the pooling (or normalization) into a single 100ng amplicon library. The final concentration of the pooled library was assessed with the KAPA qPCR Library Quantification Kit (KAPA Biosytems, USA) following the manufacturers recommended protocol. The prepared pooled library was run on an Illumina MiSeq Desktop Sequencer using a 600-cycle pair-end reagent kit (MiSeq Reagent Kits v3) at a concentration of $15 \mathrm{nM}$ with the addition $25 \%$ PhiX Control v3 (Illumina). A standard demultiplexing protocol was employed that generated FASTQ files for all barcoded samples in the pooled library.

\section{Bioinformatics}

All analyses were carried out using R 3.6 (R Core team, 2020). We curated DNA sequence data in two steps (see Appendix A1). Firstly, the sequence reads subsequently passed through a DADA2-based pipeline [37]. Specific details are available at www.nemabiome.ca. Primers were removed with Cutadapt [38] after the removal of ambiguous bases. Then, reads were discarded based on the number of errors (> 2 and $>5$ in forward and reverse reads respectively), length ( $<50 \mathrm{bp}$ ) and quality (truncG $=2$ and phiX genome). Clean forward and reverse reads were merged only if they overlapped by $>12$ bp with low mismatches (i.e., max. 3 for $>100$ bp, max. 2 for $>50$ bp and 1 for $<50$ bp reads). Putative chimeras were automatically removed but we verified the effect of this filtering on the dataset post-analysis, as these programs are known to produce a lot of false positives [39]. A conservative approach was used for taxonomic assignment of ASVs in which three different assignment methods were used (Appendix A2): (1) IDTaxa using the default conservative threshold of 60 , which corresponds to the confidence at which to truncate the output taxonomic classification [40], (2) assignTaxonomy [37, 41] and (3) BLASTn [42]. 
The nematode ITS-2 rDNA database 1.1.0 [43] containing 9811 complete and non-redundant sequences, with a few additional manual corrections of species assignation corresponding to morphotypes, was used for both IDTaxa and assignTaxonomy. (3) BLASTn, where the three best hits were considered only if they reached a threshold of $90 \%$ similarity against NCBI database sequences (2021/04/13). All specieslevel assignments were ascribed a 'confidence level' (Appendix A2) : High confidence indicates that all 3 methods assigned to the same species and moderate confidence indicates that 2 out of the 3 methods agree at the species level and also the third method was in aggreement but could only assign to the genus level. Taxonomic assignment was limited to the genus level when there was disagreement across any of the three methods at the species level (but consistency at the genus level).

Raw ASV dataset was curated following a procedure developed by Taberlet et al. (2018), see also De Barba et al. (2014) for a visualization of each step expectation and Calderón-Sanou et al. (2020) for the consequence of each step of the data curation on the final data set. Amplicon sequence variants (ASV) observed only once in the whole data set were considered spurious and were removed. [46] To delete potential contaminants [47], we discarded any ASV more abundant in negative controls ( $\max 55$ reads) than in other samples and reads with $<0.13 \%$ (maximizing the removal of sequences with low abundance in controls) of the total ASV abundance in the entire dataset. We only kept ASVs identified as gastrointestinal nematodes at least to the genus level. Finally, any samples with $<1000$ reads were removed.

\section{Phylogeny}

A phylogenetic analysis of ASV was conducted using a maximum likelihood tree with the HKY + G [49] model according to "ModelTest" function [50, 51]. We used FigTree 1.4.4 [52] to visualize ASV phylogeny. "Although the generation of ASVs enables genetic diversity to be characterized to the highest resolution, the biological relevance of much of this diversity remains unknown. The main drawback to using ASVs to characterize genetic diversity is large population sizes are required to allow for statistically significant comparisons to be made between populations. To overcome this hurdle we also clustered ASVs into "taxa".

\section{Statistical analyses on measures of parasitic community}

We removed the lungworm Varestrongylus from the dataset because the focus of the present study was on gastrointestinal nematodes. In order to control the representativeness of the data, we drew the accumulation curves for the ASV,and taxa with the "exact" method of the function "specaccum" of the package vegan [53]. Instead of the exact read count per sample and items, we used the relative frequencies of reads. The read relative frequencies in samples were plotted with ggtree [54]. After controlling for the year, the capture date, the epg and the number of L3 used for DNA extraction, we assessed the effects of age (i.e., young $<1$ year or adults) and sex (i.e., males or females) on two proxies of diversity of gastrointestinal nematodes community: alpha (measure of community diversity within individual samples) and beta (measure of comparison of dissimilarity between each pair of samples). 
We measured the beta diversity by using the Bray-Curtis dissimilarity matrices, and the alpha diversity by computing three indices: richness (the number of different items), Shannon-Weaver index [55] and Simpson index (1-D) [56] indices to estimate the alpha diversity. The Shannon-Weaver index is less robust than the Simpson index when several items are at low frequencies because Shannon-Weaver index is more sensitive to rare species and could give more accurate results depending on the taxonomic levels of item identification (e.g., ASV, or taxa).

As we had hypothesized there might be differences among the nemabiome of individuals of different age, sex and site/sector of Chizé, we tested for the influence of these factors, and their interactions, on the alpha and beta-diversity. Age and sex effects were first assessed at broad scale with the 2 sites (Chizé and Trois Fontaines) and, second, at the local scale, comparing the 3 sectors of Chizé (rich coppices, medium coppices and poor beech stand). We used generalized linear models in a model selection approach to test the effect of site, sex, and age of individuals on the alpha diversity, with a Poisson family for richness, a Gaussian family for Shannon and a Gaussian (with logit link because Simpson index ranges from 0 to 1) family for Simpson. For the beta diversity, we used a custom function to compute the Akaike's Information Criterion corrected for small sample size (AICC) based on residual sums of squares [57]. Following the recommendations of Burnham and Anderson [58], we identified models that are biologically meaningful and considering limits due to the sample size. It resulted in 18 competitive models.

We then ranked the models for each set of candidate models using the AICC, and calculated $\triangle \mathrm{AICC}$ and AICc weights. We selected the model with the lowest AICc value. Models with $\triangle \mathrm{AICC} \leq 2$ were considered equivalent [58], and in this case, we considered the most parsimonious one, i.e., the model with the lowest degree of freedom.

Differences in nemabiome between individuals (beta diversity) were visualized with a non-metric multidimensional scaling (NMDS) with 2 dimensions because NMDS well represented community data on only 2 dimensions and Bray-Curtis dissimilarities are non-Euclidean embeddable distances [59]. We verified the consistency of patterns between samples resulting from the 2 taxonomic levels with Procrustes analyses.

\section{Results}

\section{Parasite sampling}

ITS-2 rDNA nemabiome analyses were performed on 149 samples $(\mathrm{n}=36$ and 113 samples in Trois Fontaines and Chizé, respectively; Table 1, Fig. 1). A few roe deer were recaptured during the second year of sampling ( $\mathrm{n}=2$ and 17 in Trois Fontaines and Chizé, respectively). The limited number of recaptures prevents us from considering individuals as a random factor in the analyses, and because the nemabiome of recaptured deer did not present particular patterns (see Appendix A4), information regarding recapture status was not considered in the following analyses. The year of sampling had no 
influence on the nemabiome (Adonis test and Kruskal-Wallis rank sum test; see Appendix A6), and this factor was therefore not considered in the following analyses.

Table 1

Summary of samples collected in the sites of Chizé and Trois Fontaines in 2018 and 2019.

\begin{tabular}{|c|c|c|c|c|c|c|}
\hline & & \multicolumn{2}{|l|}{2018} & \multicolumn{2}{|l|}{2019} & \multirow{2}{*}{$\begin{array}{l}\text { Total } \\
(\mathrm{N}=149)\end{array}$} \\
\hline & & $\begin{array}{l}\text { Chizé } \\
(N=57)\end{array}$ & $\begin{array}{l}\text { Trois- } \\
\text { Fontaines } \\
(\mathrm{N}=22)\end{array}$ & $\begin{array}{l}\text { Chizé } \\
(N=56)\end{array}$ & $\begin{array}{l}\text { Trois- } \\
\text { Fontaines } \\
(\mathrm{N}=14)\end{array}$ & \\
\hline Sex & $\begin{array}{l}\text { F:Female; } \\
\text { M:Male }\end{array}$ & $32 \mathrm{~F} 25 \mathrm{M}$ & $10 \mathrm{~F} 12 \mathrm{M}$ & $26 \mathrm{~F} 30 \mathrm{M}$ & $5 \mathrm{~F} 9 \mathrm{M}$ & $73 F 76 M$ \\
\hline $\begin{array}{l}\text { Age } \\
\text { class }\end{array}$ & $\begin{array}{l}\text { Y:Young; } \\
\text { A:Adult }\end{array}$ & $11 Y 46 A$ & $13 Y 9 A$ & 17Y 39A & $5 Y 9 A$ & $46 Y 103 A$ \\
\hline $\begin{array}{l}\text { Eggs } \\
\text { per } \\
\text { gram }\end{array}$ & $\begin{array}{l}\text { median } \\
\text { [min-max] }\end{array}$ & 15 [0-270] & $7.5[0-60]$ & $7.5[0-90]$ & $\begin{array}{l}11.25[7.5- \\
180]\end{array}$ & 7.5 [0-270] \\
\hline $\begin{array}{l}\text { Number } \\
\text { of L3 }\end{array}$ & $\begin{array}{l}\text { median } \\
\text { [min-max] }\end{array}$ & $\begin{array}{l}156[10.75- \\
1250]\end{array}$ & $\begin{array}{l}69.3 \text { [18- } \\
8650]\end{array}$ & $\begin{array}{l}69.5 \text { [10- } \\
819]\end{array}$ & 51 [10-519] & 80 [10-8650] \\
\hline \multirow[t]{2}{*}{ Reads } & Total & 630926 & 320112 & 555517 & 156868 & 1663423 \\
\hline & $\begin{array}{l}\text { median } \\
\text { [min-max] }\end{array}$ & $\begin{array}{l}11315 \\
{[1638-} \\
22744]\end{array}$ & $\begin{array}{l}14308 \\
{[1595-} \\
33527]\end{array}$ & $\begin{array}{l}9855.5 \\
{[2749-} \\
19837]\end{array}$ & $\begin{array}{l}10288 \\
{[2436-} \\
24330]\end{array}$ & $\begin{array}{l}10631 \\
{[1595-} \\
33527]\end{array}$ \\
\hline \multirow[t]{2}{*}{ ASV } & Total & 53 & 47 & 55 & 33 & 100 \\
\hline & $\begin{array}{l}\text { median } \\
\text { [min-max] }\end{array}$ & 9 [3-16] & $12[6-17]$ & 9 [4-17] & 9 [2-19] & 9 [2-19] \\
\hline \multirow[t]{2}{*}{ Taxa } & Total & 8 & 10 & 10 & 11 & 14 \\
\hline & $\begin{array}{l}\text { median } \\
\text { [min-max] }\end{array}$ & $4[2-5]$ & $5[3-7]$ & $4[2-7]$ & $4[1-7]$ & $4[1-7]$ \\
\hline
\end{tabular}

The median number eggs per gram of feces was low and heterogeneous (7.5 eggs/g $\left.[0 ; 114]_{95 \% / Q R}\right)$, as well as the number of $L 3$ used for DNA extraction (80 [12; 993 $]_{95 \% I Q R} ;$ Table 1, Fig. 2). Both had no significant effects on alpha and beta diversity (Pearson correlation test and Adonis test; see appendix A6).

\section{Taxonomic and Community diversity}

Considering the whole dataset, we detetected 100 ASVs resolved across14 taxa of gastrointestinal nematodes (Table 1 and AppendixA2). ASVs were identified either at genus (38\%), or species $(62 \%)$ levels 
(Appendix A2). A total of 10 genera, including 11 species were identified and their phylogeny was consistent with previous knowledge on nematode taxonomy (Appendix A5). Sampling captured most of the taxa as the taxa- accumulation curves reach rapidly a plateau (Appendix A3). Procrustes analyses performed on ASV with taxa have tight correlations $(p=0.001)$. Thus, we only show results at ASV taxonomic level, but results from taxa are available in Appendix A7-A9.

According to the best models (Table 2; appendix A8), the taxonomic richness was higher in Trois Fontaines than in Chizé (estimate \pm standard error, $\beta=0.20 \pm 0.06, p=0.002$ ). The Shannon index, which is more sensitive to rare species, included significant interactions between age and site, indicating a higher diversity in young than in adult roe deer in Trois Fontaines $(\beta=0.26 \pm 0.13, p=0.038)$ (Fig. 3; Table 2). At the local scale of Chizé, no differences between the 3 sectors were detected for all alpha diversity indexes (Fig. 2).

Table 2

Best generalized linear models selected for ASVs and each diversity index (Richness, Simpson, Shannon).

\begin{tabular}{|c|c|c|c|c|c|}
\hline $\begin{array}{l}\text { Diversity } \\
\text { index }\end{array}$ & Best generalized models selected & Variables & $\begin{array}{l}\text { Parameter } \\
\text { estimate } \pm \text { SE }\end{array}$ & $\begin{array}{l}\text { z-val. or } \\
\text { t-val. }\end{array}$ & $\mathbf{p}$ \\
\hline \multirow[t]{2}{*}{ Richness } & \multirow{2}{*}{$\alpha \backslash$ tildesite } & intercept & $2.13 \pm 0.03$ & 65.89 & $\star \star \star *$ \\
\hline & & siteTF & $0.20 \pm 0.06$ & 3.16 & $\star \star$ \\
\hline \multirow[t]{4}{*}{ Simpson } & \multirow{4}{*}{$\alpha \backslash$ tildeage + site + age $\times$ site } & intercept & $0.98 \pm 0.06$ & 17.37 & *** \\
\hline & & siteTF & $0.07 \pm 0.14$ & 0.52 & - \\
\hline & & ageY & $0.06 \pm 0.12$ & 0.54 & - \\
\hline & & ageY:siteTF & $0.37 \pm 0.24$ & 1.57 & - \\
\hline \multirow[t]{4}{*}{ Shannon } & \multirow{4}{*}{$\alpha \backslash$ tildeage + site + age $\times$ site } & intercept & $1.59 \pm 0.03$ & 46.23 & $\star * *$ \\
\hline & & siteTF & $0.11 \pm 0.08$ & 1.36 & - \\
\hline & & ageY & $0.01 \pm 0.07$ & 0.14 & - \\
\hline & & ageY:siteTF & $0.26 \pm 0.13$ & 2.09 & * \\
\hline
\end{tabular}

Gaussian families were used for Simpson and Shannon regression and Poisson family for Richness. The effect of site (Chizé as reference), age (adult as reference), sex (females as reference) and the interaction between them are reported when including in the selected models. Parameter estimates with SD are reported with the corresponding z-value (Poisson family) or t-value (Gaussian family) and $p$-value. Statistical significance is represented by * for $p<0.05$, ** for $p<0.01$ and $* \star \star$ for $p<0.001$.

According to the most parsimonious model selected for the Bray-Curtis dissimilarity the differences of nemabiome between samples were mostly explained by the site $\left(F_{1,145}=37.41, R^{2}=0.19, p=0.001\right)$ and age $\left(F_{1,145}=14.35, R^{2}=0.07, p=0.001\right)$ variables, and the differences between adult and young roe deer were slightly more pronounced in Trois Fontaines $\left(F_{1,145}=4.04, R^{2}=0.02, p=0.004\right)$ (Table 3). Similarly, we observed distinct groups in the NMDS, with partially separated clouds of points for Chizé and for Trois 
Fontaines, and a marked separation for young and adult roe deer in Trois Fontaines (Fig. 4). Locally in Chizé, the selected model for Bray-Curtis dissimilarity depended only on age $\left(F_{1,111}=6.62, R^{2}=0.06, p=\right.$ 0.003).

Table 3

PerMANOVA model selected for ASVs and Bray-Curtis dissimilarities matrix.

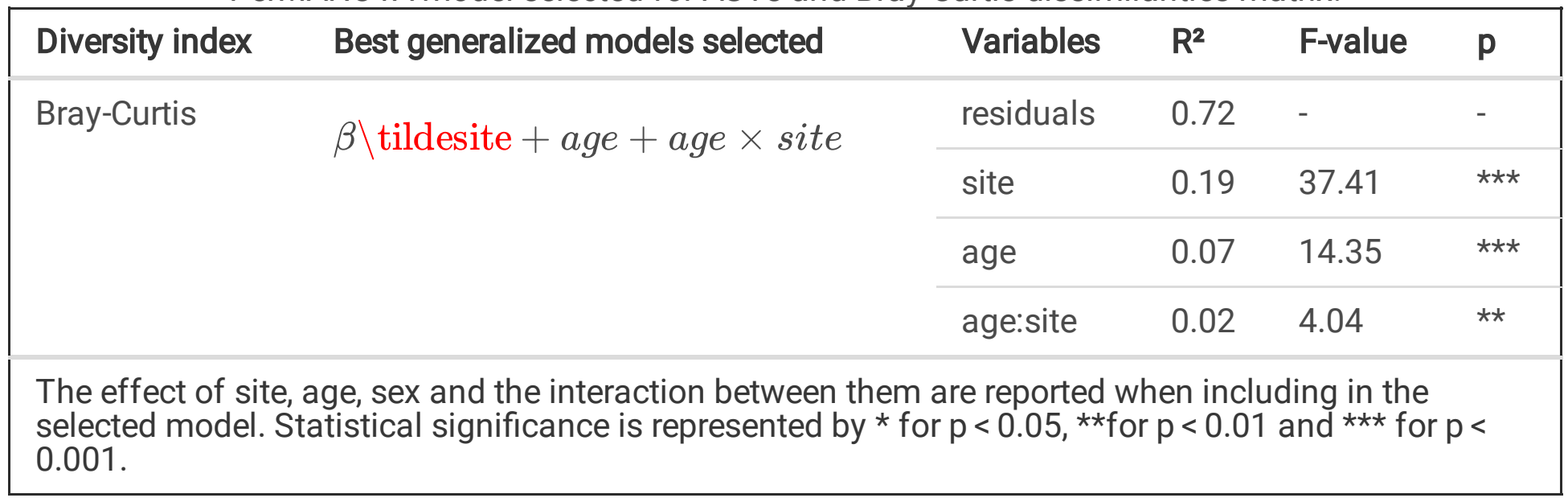

The most common species/genus in the entire dataset were Ostertagia leptospicularis, Trichostrongy/us spp. and Spiculopteragia spiculoptera present in 139, 121, 120 samples of roe deer $(93 \%, 81 \%$ and $81 \%$, respectively) with a mean relative abundance among those samples of $44 \%, 29 \%$ and $17 \%$, respectively (Fig. 2). In Chizé, Ostertagia leptospicularis, Trichostrongylus spp. and Spiculopteragia spiculoptera were present in $98 \%, 71 \%, 79 \%$ of samples in the sector $1 ; 93 \%, 80 \%, 90 \%$ in the sector 2 ; and $100 \%, 86 \%, 100 \%$ in the sector 3 . The mean relative abundance of species among those samples were $53 \%, 22 \%, 17 \%$ (sector 1), 46\%, 28\%, 23\% (sector 2) and 45\%, 33\%, 19\% (sector 3). In Trois Fontaines, Ostertagia leptospicularis, Trichostrongylus spp. and Spiculopteragia spiculoptera were present in $81 \%, 97 \%$ and $64 \%$ of samples with a mean relative abundance among those samples of $24 \%, 42 \%$ and $9 \%$. Chabertia ovina, Haemonchus contortus and Bunostomum trigonocephalum were only detected in Trois Fontaines (Fig. 5 and Fig. 2), explaining the significantly higher richness in Trois Fontaines (Table 2) and the significative difference of nemabiome between the two site (Table 3). We also observed variations in the prevalence and relative abundance of 5 ASV of Trichostrongylus spp. between the two sites, between the age of the host, but with an higher differences of abduncance between age in Trois Fontaines in comparison with Chizé (Fig. 5), as indicated by the significant interaction between site and age on Shannon, and Bray-Curtis diversity indices.

\section{Discussion}

The ITS-2 rDNA nemabiome metabarcoding provided unique fine level resolution data on the gastrointestinal nematode parasite community composition of two populations of roe deer in France. The gastrointestinal nematode species detected in Trois Fontaines and Chizé correspond largely to species previously detected on necropsies of roe deer in the two study sites [16]. We also detected species not previously described in these two populations, but previously found in other roe deer populations (e.g., in 
Spain: [60]; and in the Netherlands: [61]). This study provided also new insights on site- and age-specific gastrointestinal nematode diversity as we showed that young roe deer have different nemabiome compared to adults, with more pronounced effects of age in Trois Fontaines.

\section{Diversity of gastrointestinal nematodes in roe deer}

In accordance with previous studies on helminths of roe deer (e.g., [60, 62]), the main species detected were 0 . leptospicularis, Trichostrongylus spp. and Spiculopteragia spp. These gastrointestinal nematodes are commonly found in roe deer, confirming our hypothesis $\mathrm{H} 1$ that the dominant nematode species should be roe deer-specific parasites given that the roe deer populations are enclosed in fenced forest areas. However, we found some differences between the two study sites. We have detected generalist species, i.e, gastrointestinal nematodes species found in different host species, at a relatively high frequency in Trois Fontaines but not in Chizé. In addition to $C$. ovina previously detected in Trois Fontaines [16], we have detected for the first time the presence of the highly pathogenic species $H$. contortus and B. trigonocephalum in this population. In Chizé and Trois Fontaines, we noted the presence of $T$. axei and $O$. venulosum, at low relative abundance, also considered as generalist species, and $T$. colubriformis (only in Chizé) and T. circumcincta, mostly parasitizing sheep and goats [11, 63]. The identification of $H$. contortus and $T$. axei is at a "high confidence level' because these species were well represented in the nemabiome database and the three different methods of assignment provided the same species assignment. For $B$. trigonocephalum ASVs were only assigned at the moderate confidence level including a relatively low level of identity ( $92 \%$ over $283 \mathrm{bp}$ (query cover of $100 \%$, e-value $=9 \mathrm{e}^{-110}$ ) to the best BLAST hit in Genebank (Appendix A2). To our knowledge, B. trigonocephalum and $B$. phlebotomum are the only species among the Bunostomum genus which were identified in roe deer in Europe (e.g., [61]). These two species are highly divergent, and considering the low-level of intra-specific variation observed within $B$. trigonocephalum [64], it is possible that the Bunostomum species identified in Trois Fontaines is apreviously unidentified, or cryptic, species closely related to $B$. trigonocephalum.

For some ASVs, the taxonomic identification did not reach the species level, e.g., Trichostrongylus spp., Spiculopteragia spp., or Ostertagia spp. This may be largely a due to the lack of reference sequence available for these species in the nemabiome database and ultimately in GenBank. This issue is accentuated when applying nemabiome metabarcoding to wildlife hosts than domestic livestock where parasite communites are better defined. For example, there is just a single ITS-2 reference sequence for Trichostrongylus capricola in comparison to 299 ITS-2 reference sequences for Haemonchus contortus in the nemabiome database (see also Aivelo and Medlar 2018 for the SILVA database). The potential presence of cryptic species and/ or hybrids of closely-related species [65], may futher complicate accurate species assignation. Consequently, the generation of reference sequences from morphologically validated parasites should continue to be a research priority for scientific community as a whole.

Ashworthius sidemi was not detected in Trois Fontaines, although it has previously been isolated from bodies during winter in this study area $[16,66]$. This may be due to the hypobiosis in this species [67] or to the fact that during winter, females contained only non-embryonated eggs [68]. Further investigations 
on the seasonal nemabiome will be required to determine the complete gastrointestinal nematode species richness and variations during the year and species.

\section{Effects of site, age and sex class on the nemabiome}

In both study sites, age had a major influence on the gastrointestinal nematode species community composition in roe deer, with a higher diversity observed in young compared to adult animals in accordance with our predictions $(\mathrm{H} 2)$. This age effect is mostly driven by some specific variants of Trichostrongylus spp. in both sites, and of $\mathrm{H}$. contortus in Trois Fontaines that are more prevalent and of higher relative abundance in young roe deer compared to adults. The limited influence of age on prevalence and relative abundance observed for some of the other parasite species (see also e.g., SantínDurán et al. 2008) may result from survival mechanisms of these parasite species [69] or from an already developed and efficient immune response of the host when young roe deer were captured against these parasite species (i.e., at 8-10 months of age in our study), or an immune response that is inefficient.

The higher prevalence and relative abundance of some gastrointestinal nematodes species found in adults in Chizé but not in Trois Fontaines suggest a higher ability to control certain parasite species (e.g., some Trichostrongylus variants) in adult roe deer in Trois Fontaines. There is probably a synergistic interaction between the body condition of roe deer, their immune response and the richness of parasites to which they have been exposed [14]. Individuals in lower body condition are more susceptible to parasite infection or/and high levels of parasitism is suspected to negatively impact body condition [70]. Such negative correlation between physiological performance and parasitic burden was observed to be more pronounced in Chizé than in Trois Fontaines [71]. In addition, in Trois Fontaines, the higher body condition of roe deer [28] and strongyle species diversity may have allowed roe deer to invest in innate immunity [72], which could prevent the establishment or facilitate the expulsion of strongyles [73]. In contrast, roe deer in Chizé, exposed to a lower species richness of strongyles and being in lower body condition, invest more in adaptive response, which is considered less costly than innate response [74].

Contrary to our expectation $(\mathrm{H} 3)$, the diversity of strongyles do not differ between males and females. Indeed, the probability of exposure to gastrointestinal species are equal beween males and females as they do not spatially segregate [75] and few sexual differences in their feeding behavior or activity have been observed between males and females $[76,77]$. In addition, no sex-specific physiological status diverting or limiting the allocation of resources to parasite defenses such as young nursing [4] or rut [78] occurred during the study period. Sampling during such sex-specific energetically costly periods could be pertinent to consider to better understand the mechanisms underlying sex and age differences in gastrointestinal nematodes communities.

Despite the differences in habitat quality, the nemabiome of roe deer was not different between the three sectors of Chizé (H4). This suggests that local ecological variation, and the resulting differences in body conditions among roe deer inhabiting these different habitats [33], does not affect the nemabiome. It can be explained by the movement of roe deer among sectors that can spread the parasites among the feeding areas $[33,79]$. 


\section{Detection of parasite species commonly observed in domestic ungulates}

The occurrence in roe deer of Trois Fontaines of parasites commonly detected in small domestic ruminants, including highly pathogenic species (e.g. H. contortus, B. trigonocephalum), confirmed that wildlife share parasites found in livestock (e.g., $[62,80])$. This supports our concern of possible contamination by domestic sheep despite the roe deer population of Trois Fontaines is in a fenced area and has no contact or shared pastures with domestic ungulates. To our knowledge, only 4 to 6 domestic sheep have been bred near to the fence (C. Warnant, pers. com.), on the other side of a road surrounding the reserve, for several years. It is not known whether generalist parasites are freely shared between domestic sheep and roe deer, or whether they evolve separately between these hosts without crosscontamination, and this remains to be determined. Comparing the genetic signatures of helminths [79] on the reserve with those of sheep around the reserve would contribute to clarify this issue. The consequences of these pathogenic species on roe deer fitness remain to be determined.

\section{Conclusion}

In the present study we investigate the gastrointestinal nematode species community composition in two isolated populations of roe deer using ITS-2 rDNA nemabiome metabarcoding. We found that most gastrointestinal nematodes found in the two sites are parasites classically found in this species. Even though the two populations inhabit fenced areas, we also observed gastrointestinal nematodes usually found in domestic ungulates in one of the populations (Trois Fontaines). The only known potential source of these parasite species were a small group of sheep, grazing in a separately fenced region indicating the potentially high capacity of expension of those generalist gastrointestinal nematodes species in a naive ungulate population but further analyses are needed to test this hypothesis. This could have strong implications for the management of wild populations and the introduction of non-native species to wildlife communities. Therefore it appears highly relevant to study roe deer and domestic ungulates living in sympatry in anthropogenic landscapes dominated by farmland in order to better understand the dynamic of gastrointestinal nematodes among wild and domestic populations and the risk of cross-transmission. This work also illustrated the power and limitations of ITS-2 neambiome metabarcoding for such wildlife studies.

\section{Declarations}

\section{Acknowledgments}

The authors warmly thank all the professionals from the Office Français de la Biodiversite and all the trainees for data collection. This project was founded by Results Driven Agriculture Research (RDAR; grant number 2017R021R), University of Calgary, the Office Français de la Biodiversité, the NSERCCREATE (Canada) Host Parasite Interactions (HPI) graduate training program and VetAgro Sup - Pôle d'Expertise Vétérinaire et Agronomique des Animaux Sauvages (EVAAS ; http://evaas.vetagro-sup.fr/; 
DGAL - VetAgro Sup -INRAE funding). G Bourgoin was supported by the AgreenSkills+ fellowship program (EU program; Marie-Curie FP7 COFUND People Programme ; grant agreement n_609398).

\section{Ethics approval and consent to participate}

Protocol approved by the Director of Food, Agriculture and Forest (Prefectoral order 2009-14 from Paris)

\section{Consent for publication}

Not applicable

\section{Availability of data and materials}

The datasets used and/or analysed during the current study are available from the corresponding author on reasonable request.

\section{Competing interests}

The authors declare that they have no competing interests.

\section{Funding}

See Aknowledgments section

\section{Authors' contributions}

Study design was completed by GB and JG. Captures of roe deer and sampling were performed by GC, SC, FD, JD, SP and BR. Fecal analyses and DNA extraction were completed by by SB and MTP. All samples were prepared for sequencing by LR, JDR and JW and all data analyses were completed by LR, $\mathrm{CB}, \mathrm{JDR}$ and JW. CB, GY and GB wrote the manuscript. All other authors contributed to the critical review and editing of the manuscript. All authors read and approved the final manuscript.

\section{References}

1. Hoberg EP, Kocan AA, Rickard LG. Gastrointestinal strongyles in wild ruminants. In: Samuel WM, Pybus MJ, Kocan AA, editors. Parasitic diseases of wild mammals. Ames: lowa State University Press; 2001. pp. 193-227.

2. Roeber F, Jex AR, Gasser RB. Impact of gastrointestinal parasitic nematodes of sheep, and the role of advanced molecular tools for exploring epidemiology and drug resistance - an Australian perspective. Parasites Vectors. 2013;6:153.

3. Craig BH, Pilkington JG, Pemberton JM. Gastrointestinal nematode species burdens and host mortality in a feral sheep population. Parasitology. 2006;133:485-96.

4. Leivesley JA, Bussière LF, Pemberton JM, Pilkington JG, Wilson K, Hayward AD. Survival costs of reproduction are mediated by parasite infection in wild Soay sheep. Ecol Lett. 2019;22:1203-13. 
5. Kelehear C, Brown GP, Shine R. Influence of lung parasites on the growth rates of free-ranging and captive adult cane toads. Oecologia. 2011;165:585-92.

6. Tompkins DM, Wilson K. Wildlife disease ecology: from theory to policy. Trends Ecol Evol. 1998;13:476-8.

7. Gunn A, Irvine RJ. Subclinical parasitism and ruminant foraging strategies: a review. Wildl Soc Bull. 2003;31:117-26.

8. Thompson RCA, Lymbery AJ, Smith A. Parasites, emerging disease and wildlife conservation. Int J Parasitol. 2010;40:1163-70.

9. Dobson A, Lafferty KD, Kuris AM, Hechinger RF, Jetz W. Homage to Linnaeus: how many parasites? How many hosts? Proceedings of the National Academy of Sciences. National Academy of Sciences; 2008;105:11482-9.

10. Goater TM, Goater CP, Esch GW. Parasitism: the diversity and ecology of animal parasites. Cambridge: Cambridge University Press; 2013.

11. Taylor MA, Coop RL, Wall RL. Veterinary Parasitology. Fourth. Wiley-Blackwell; 2015.

12. Budischak SA, O'Neal D, Jolles AE, Ezenwa VO. Differential host responses to parasitism shape divergent fitness costs of infection. Funct Ecol. 2018;32:324-33.

13. Lochmiller RL, Deerenberg C. Trade-offs in evolutionary immunology: just what is the cost of immunity? Oikos. 2000;88:87-98.

14. Beldomenico PM, Begon M. Disease spread, susceptibility and infection intensity: vicious circles? Trends Ecol Evol. 2010;25:21-7.

15. Tompkins DM, Dunn AM, Smith MJ, Telfer S. Wildlife diseases: from individuals to ecosystems. J Anim Ecol. 2011;80:19-38.

16. Body G, Ferté H, Gaillard J-M, Delorme D, Klein F, Gilot-Fromont E. Population density and phenotypic attributes influence the level of nematode parasitism in roe deer. Oecologia. 2011;167:635-46.

17. Aleuy OA, Ruckstuhl K, Hoberg EP, Veitch A, Simmons N, Kutz SJ. Diversity of gastrointestinal helminths in Dall's sheep and the negative association of the abomasal nematode, Marshallagia marshalli, with fitness indicators. PLoS One. 2018;13:e0192825.

18. Sinclair R, Melville L, Sargison F, Kenyon F, Nussey D, Watt K, et al. Gastrointestinal nematode species diversity in Soay sheep kept in a natural environment without active parasite control. Vet Parasitol. 2016;227:1-7.

19. Gruver AL, Hudson LL, Sempowski GD. Immunosenescence of ageing. J Pathol. 2007;211:144-56.

20. Peters A, Delhey K, Nakagawa S, Aulsebrook A, Verhulst S. Immunosenescence in wild animals: meta-analysis and outlook. Ecol Lett. 2019;22:1709-22.

21. Poulin R. Helminth growth in vertebrate hosts: does host sex matter? Int J Parasitol. 1996;26:13115.

22. Klein SL. The effects of hormones on sex differences in infection: from genes to behavior. Neuroscience Biobehavioral Reviews. 2000;24:627-38. 
23. Moore SL, Wilson K. Parasites as a viability cost of sexual selection in natural populations of mammals. 297: Science. American Association for the Advancement of Science; 2002. pp. 2015-8.

24. Markle JG, Fish EN. SeXX matters in immunity. Trends Immunol. 2014;35:97-104.

25. Aivelo T, Medlar A. Opportunities and challenges in metabarcoding approaches for helminth community identification in wild mammals. Parasitology. 2018;145:608-21.

26. Avramenko RW, Redman EM, Lewis R, Yazwinski TA, Wasmuth JD, Gilleard JS. Exploring the gastrointestinal "Nemabiome": deep amplicon sequencing to quantify the species composition of parasitic nematode communities. PLoS One. 2015;10(12):e0143559.

27. Walker JG, Morgan ER. Generalists at the interface: nematode transmission between wild and domestic ungulates. International Journal for Parasitology: Parasites Wildlife. 2014;3:242-50.

28. Gilot-Fromont E, Jégo M, Bonenfant $C$, Gibert P, Rannou B, Klein F, et al. Immune phenotype and body condition in roe deer: individuals with high body condition have different, not stronger immunity. PLoS One. 2012;7:e45576.

29. Cheynel L, Lemaître J-F, Gaillard J-M, Rey B, Bourgoin G, Ferté H, et al. Immunosenescence patterns differ between populations but not between sexes in a long-lived mammal. Sci Rep. 2017;7:13700.

30. O'Connor LJ, Walkden-Brown SW, Kahn LP. Ecology of the free-living stages of major trichostrongylid parasites of sheep. Vet Parasitol. 2006;142:1-15.

31. Santín-Durán M, Alunda JM, Hoberg EP, de la Fuente C. Age distribution and seasonal dynamics of abomasal helminths in wild red deer from central Spain. J Parasitol. 2008;94:1031-7.

32. Froeschke G, Harf R, Sommer S, Matthee S. Effects of precipitation on parasite burden along a natural climatic gradient in southern Africa - implications for possible shifts in infestation patterns due to global changes. Oikos. 2010;119:1029-39.

33. Pettorelli N, Gaillard J-M, Duncan P, Maillard D, Van Laere G, Delorme D. Age and density modify the effects of habitat quality on survival and movements of roe deer. Ecology. 2003;84:3307-16.

34. Gaillard J-M, Duncan P, Delorme D, Van Laere G, Pettorelli N, Maillard D, et al. Effects of hurricane Lothar on the population dynamics of European roe deer. Journal of Wildlife Management. 2003;67:767-73.

35. Gaillard J-M, Delorme D, Boutin J-M, Van Laere G, Boisaubert B, Pradel R. Roe deer survival patterns: a comparative analysis of contrasting populations. J Anim Ecol. 1993;62:778-91.

36. Raynaud J-P, William G, Brunault G. Etude de l'efficacité d'une technique de coproscopie quantitative pour le diagnostic de routine et le contrôle des infestations parasitaires des bovins, ovins, équins et porcins. Annales de Parasitologie Humaine et Comparée. 1970;45:321-42.

37. Callahan BJ, McMurdie PJ, Rosen MJ, Han AW, Johnson AJA, Holmes SP. DADA2: High-resolution sample inference from Illumina amplicon data. Nat Methods. 2016;13:581-3.

38. Martin M. Cutadapt removes adapter sequences from high-throughput sequencing reads. EMBnetjournal. 2011;17:10-2. 
39. Taberlet P, Bonin A, Zinger L, Coissac E. Environmental. DNA: for biodiversity research and monitoring. New York: Oxford; 2018.

40. Murali A, Bhargava A, Wright ES. IDTAXA: a novel approach for accurate taxonomic classification of microbiome sequences. Microbiome. 2018;6:140.

41. Wang Q, Garrity GM, Tiedje JM, Cole JR. Naïve bayesian classifier for rapid assignment of rRNA sequences into the new bacterial taxonomy. Appl Environ Microbiol. 2007;73:5261-7.

42. Altschul SF, Gish W, Miller W, Myers EW, Lipman DJ. Basic local alignment search tool. J Mol Biol. 1990;215:403-10.

43. Workentine ML, Chen R, Zhu S, Gavriliuc S, Shaw N, Rijke J de, et al. A database for ITS2 sequences from nematodes. BMC Genet. 2020;21:74.

44. De Barba M, Miquel C, Boyer F, Mercier C, Rioux D, Coissac E, et al. DNA metabarcoding multiplexing and validation of data accuracy for diet assessment: application to omnivorous diet. Molecular Ecology Resources. 2014;14:306-23.

45. Calderón-Sanou I, Münkemüller T, Boyer F, Zinger L, Thuiller W. From environmental DNA sequences to ecological conclusions: how strong is the influence of methodological choices? J Biogeogr. 2020;47:193-206.

46. Callahan BJ, McMurdie PJ, Rosen MJ, Han AW, Johnson AJA, Holmes SP. DADA2: High resolution sample inference from Illumina amplicon data. Nature methods. 2016;13:581-3.

47. Schnell IB, Bohmann K, Gilbert MTP. Tag jumps illuminated - reducing sequence-to-sample misidentifications in metabarcoding studies. Molecular Ecology Resources. 2015;15:1289-303.

48. Callahan BJ, McMurdie PJ, Holmes SP. Exact sequence variants should replace operational taxonomic units in marker-gene data analysis. The ISME Journal. 2017;11:2639-43.

49. Hasegawa M, Kishino $H$, Yano T. Dating of the human-ape splitting by a molecular clock of mitochondrial DNA. J Mol Evol. 1985;22:160-74.

50. Posada D, Crandall KA. modeltest: testing the model of DNA substitution. Bioinformatics. 1998;14:817-8.

51. Schliep KP. phangorn: phylogenetic analysis in R. Bioinformatics Oxford Academic. 2011;27:592-3.

52. Rambaut A. (2014). FigTree v1.4.4. http://tree.bio.ed.ac.uk/software/figtree/. Accessed on 4 December 2020.

53. Oksanen J, Blanchet FG, Friendly M, Roeland K, Legendre P, McGlinn D, et al. (2020). vegan: Community Ecology Package. R package v2.5-7. https://CRAN.R-project.org/package=vegan.

54. Yu G, Smith DK, Zhu H, Guan Y, Lam TT-Y. ggtree: an R package for visualization and annotation of phylogenetic trees with their covariates and other associated data. Methods Ecol Evol. 2017;8:2836.

55. Shannon CE, Weaver W. A mathematical theory of communication. Urbana; 1948.

56. Simpson EH. Measurement of Diversity. Nature Nature Publishing Group. 1949;163:688. 
57. Dyson K. Custom community ecology helper R scripts [Internet]. 2018. Available from: https://github.com/kdyson/R_Scripts.

58. Burnham KP, Anderson DR. Model selection and multimodel inference: a practical informationtheoretic approach. 2nd ed. New York: Springer-Verlag; 2002.

59. Legendre P, Legendre L. Numerical ecology. Second. Amsterdam: Elsevier Science BV; 1998.

60. Pato FJ, Vázquez L, Díez-Baños N, López C, Sánchez-Andrade R, Fernández G, et al. Gastrointestinal nematode infections in roe deer (Capreolus capreolus) from the NW of the Iberian Peninsula: assessment of some risk factors. Vet Parasitol. 2013;196:136-42.

61. Borgsteede FHM, Jansen J, Van Nispen tot Pannerden HPM, Van Der Burg WPJ, Noorman N, Poutsma J, et al. Untersuchungen über die helminthen-fauna beim reh (Capreolus capreolus L.) in den Niederlanden. Zeitschrift für Jagdwissenschaft. 1990;36:104-9.

62. Zaffaroni E, Teresa Manfredi M, Citterio C, Sala M, Piccolo G, Lanfranchi P. Host specificity of abomasal nematodes in free ranging alpine ruminants. Vet Parasitol. 2000;90:221-30.

63. Wyrobisz-Papiewska A, Kowal J, Nosal P, Chovancová G, Rehbein S. Host specificity and species diversity of the Ostertagiinae Lopez-Neyra, 1947 in ruminants: a European perspective. Parasites Vectors. 2018;11:369.

64. Wang C, Gao J-F, Chang QC, Zou FC, Zhao Q, Zhu X-Q. Sequence variability in four mitochondrial genes among Bunostomum trigonocephalum isolates from four provinces in China. J Helminthol. 2012;87:1-6.

65. Wyrobisz A, Kowal J, Nosal P. Insight into species diversity of the Trichostrongylidae Leiper, 1912 (Nematoda: Strongylida) in ruminants. J Helminthol. 2016;90:639-46.

66. Lehrter V, Jouet D, Liénard E, Decors A, Patrelle C. Ashworthius sidemi S. 1933 and Haemonchus contortus (Rudolphi, 1803) in cervids in France: integrative approach for species identification. Infection, Genetics and Evolution. 2016;46:94-101.

67. Dróżdż J, Demiaszkiewicz A, Lachowicz J. Expansion of the Asiatic parasite Ashworthius sidemi (Nematoda, Trichostrongylidae) in wild ruminants in Polish territory. Parasitol Res. 2003;89:94-7.

68. Vadlejch J, Kyriánová I, Rylková K, Zikmund M, Langrova I. Health risks associated with wild animal translocation: a case of the European bison and an alien parasite. Biological Invasions. 2017;19.

69. Else KJ. Have gastrointestinal nematodes outwitted the immune system? Parasite Immunol. 2005;27:407-15.

70. Bourgoin G, Portanier E, Poirel M-T, Itty C, Duhayer J, Benabed S, et al. Reproductive females and young mouflon (Ovis gmelini musimon $\times$ Ovis sp.) in poor body condition are the main spreaders of gastrointestinal parasites. Parasitology. 2021;148:809-18.

71. Jégo M, Ferté $H$, Gaillard J-M, Klein F, Crespin L, Gilot-Fromont E, et al. A comparison of the physiological status in parasitized roe deer (Capreolus capreolus) from two different populations. Vet Parasitol. 2014;205:717-20. 
72. Bordes F, Morand S. Coevolution between multiple helminth infestations and basal immune investment in mammals: cumulative effects of polyparasitism? Parasitol Res. 2009;106:33-7.

73. Inclan-Rico JM, Siracusa MC. First responders: innate immunity to helminths. Trends in Parasitology. 2018;34:861-80.

74. Martin LB, Weil ZM, Nelson RJ. Seasonal changes in vertebrate immune activity: mediation by physiological trade-offs. Philosophical Transactions of the Royal Society B: Biological Sciences. 2008;363:321-39.

75. Bonenfant C, Gaillard J-M, Dray S, Loison A, Royer M, Chessel D. Testing sexual segregation and aggregation: old ways are best. Ecology. 2007;88:3202-8.

76. José CS, Lovari S, Ferrari N. Temporal evolution of vigilance in roe deer. Behav Proc. 1996;38:155-9.

77. Merceron G, Viriot L, Blondel C. Tooth microwear pattern in roe deer (Capreolus capreolus L.) from Chizé (Western France) and relation to food composition. Small Ruminant Research. 2004;53:12532.

78. Habig B, Doellman MM, Woods K, Olansen J, Archie EA. Social status and parasitism in male and female vertebrates: a meta-analysis. Sci Rep. 2018;8:3629.

79. Portanier E, Garel M, Devillard S, Duhayer J, Poirel M-T, Henri H, et al. Does host socio-spatial behavior lead to a fine-scale spatial genetic structure in its associated parasites? Parasite. 2019;26:64.

80. Barone CD, Wit J, Hoberg EP, Gilleard JS, Zarlenga DS. Wild ruminants as reservoirs of domestic livestock gastrointestinal nematodes. Veterinary Parasitology. 2020;109041.

\section{Figures}


sectors

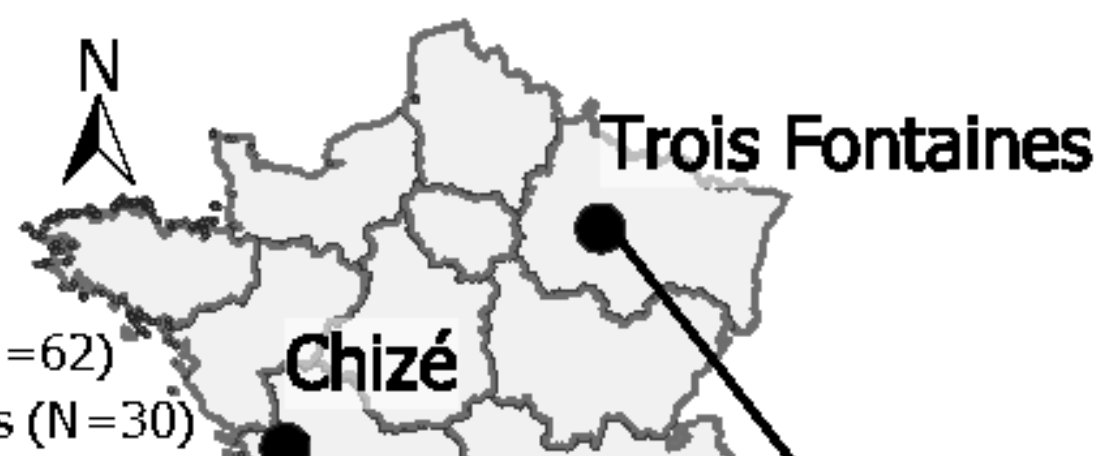

$\square$ Medium coppices $\left(\mathrm{N}=30^{\circ}\right)$

$\square$ Poor beech stand $(\mathrm{N}=21)$

$\square$ no data

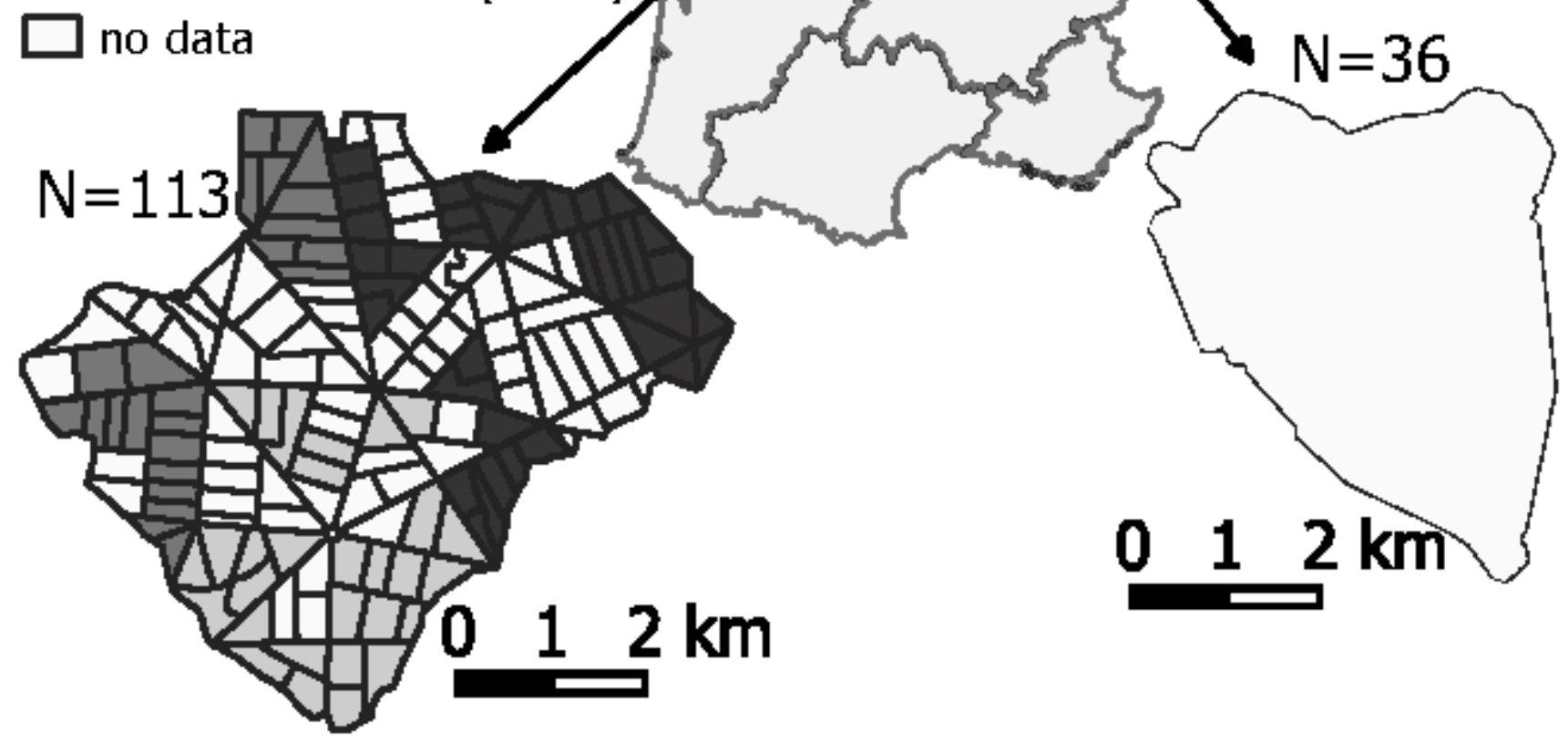

Figure 1

Sampling sites in two regions of France, where roe deer were captured. In Trois Fontaines, habitat is homogeneous with rich coppices, while in Chizé, 3 sectors with different habitat types and quality are observed (grey color gradient). $\mathrm{N}$ corresponds to sampling size within each site. 


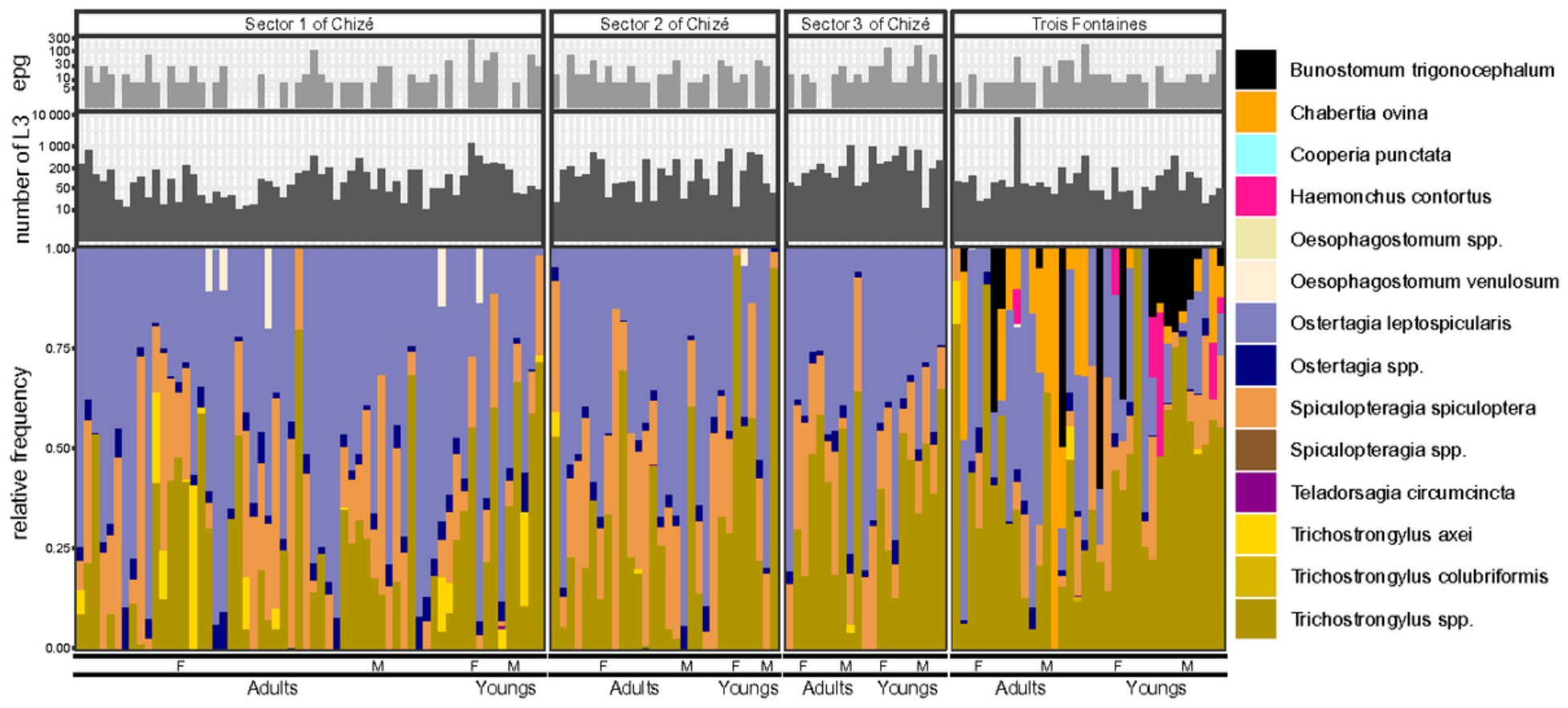

Figure 2

Egg count, number of L3 and read relative frequencies of gastrointestinal nematodes at taxa level. Each taxon is defined by one color. The data are split based on site location (Chizé or Trois Fontaines), age (young or adult roe deer) and sex (F: females and M: males). In addition, Samples from Chizé are subdivided according to the 3 different sectors: sector 1: "rich coppices", sector 2: "medium coppices", sector 3: "poor beech stand". 


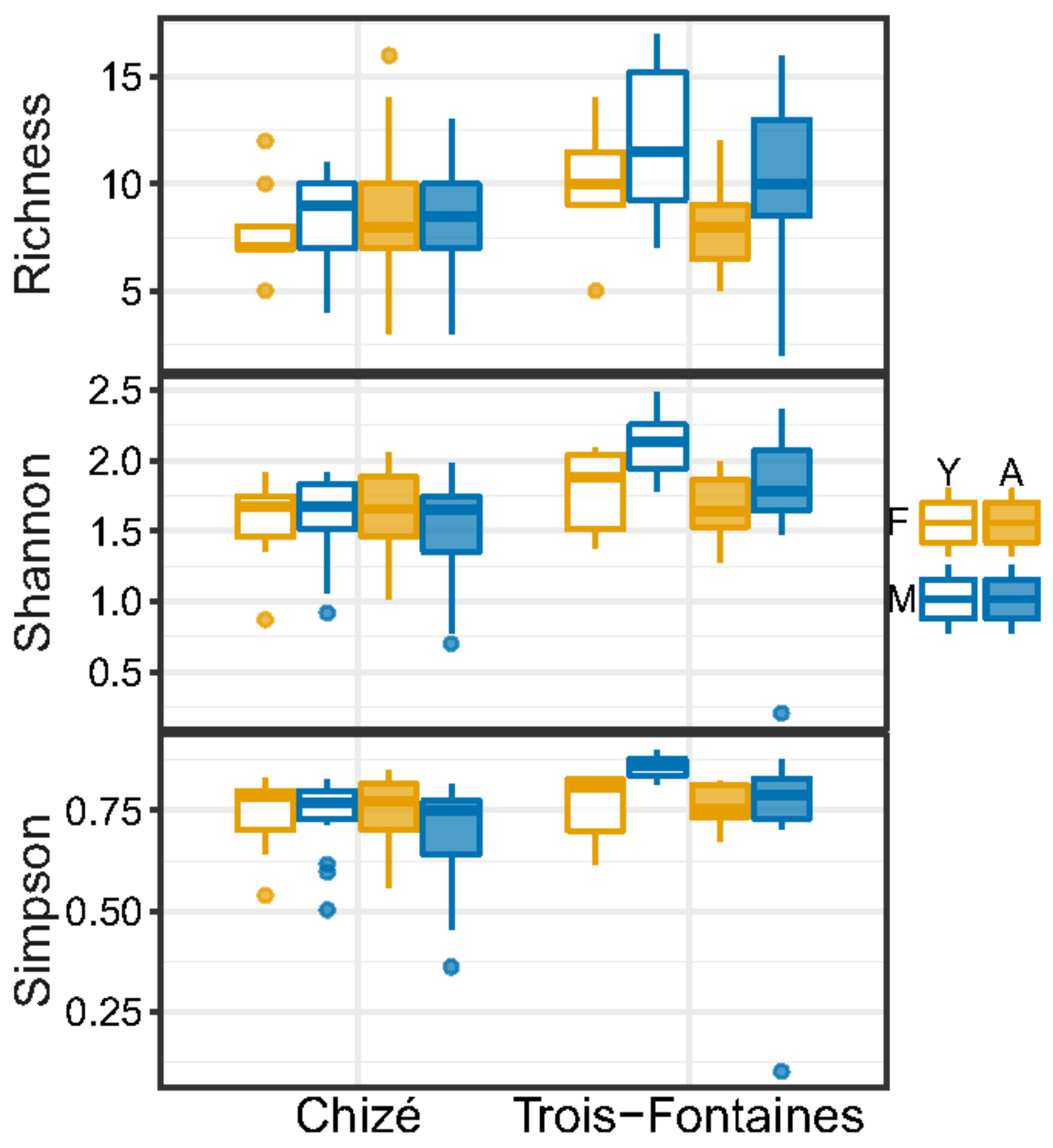

Figure 3

Box plot of richness, Shannon and Simpson index calculated on ASVs. Each box includes the 25th and 75th percentile, the median represented by the line within the box, the whiskers indicating the 10th and 90th percentiles and points above and under each box are outliers. Factors correspond to roe deer of different ages (Y: young, A: adult) and sex (M: male, F: female) in Chizé and Trois Fontaines. 


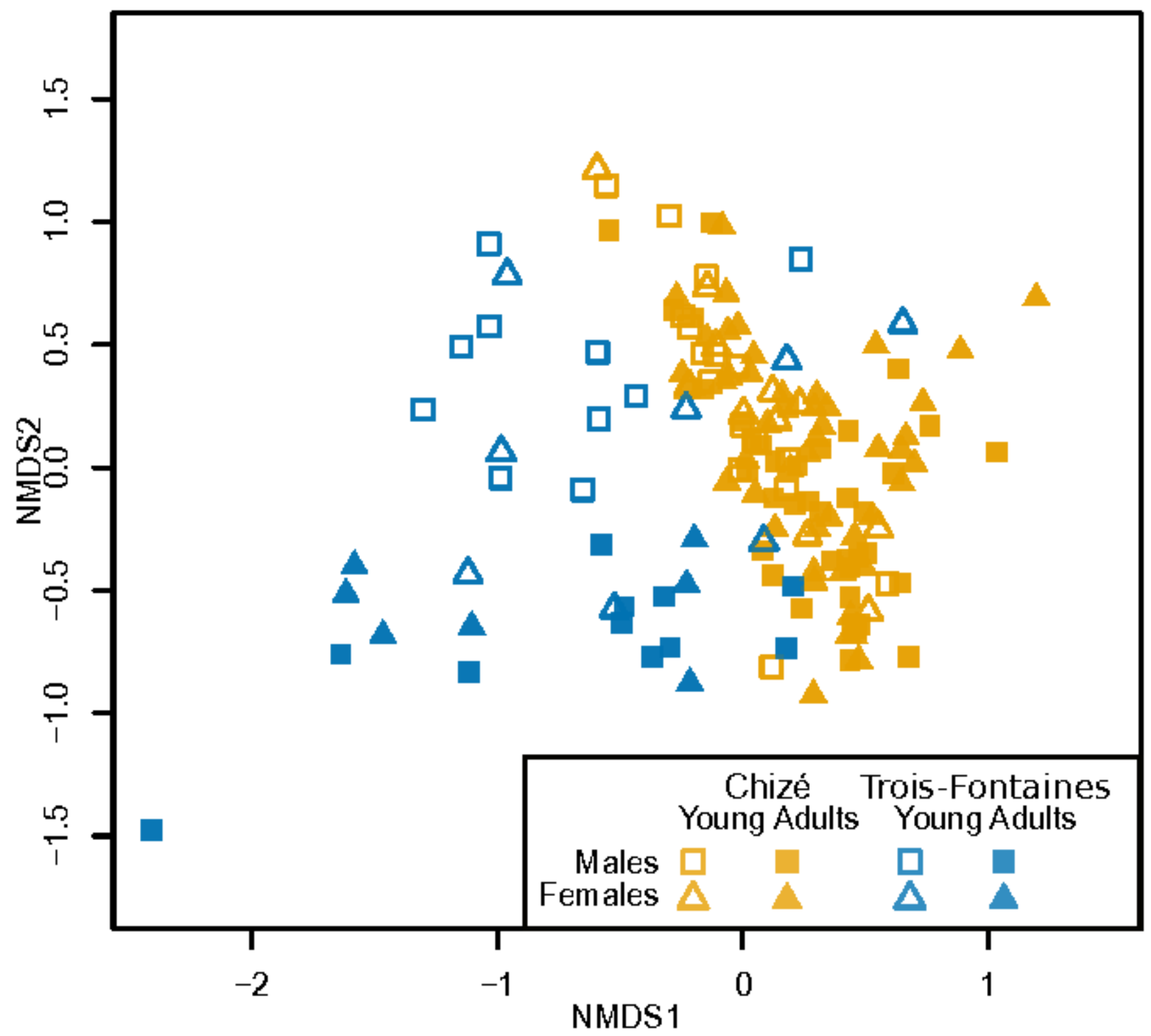

Figure 4

Non-metric Multidimensional Scaling of nemabiome based on 89 ASVs from the 149 roe deers. Age (young and adult), sex (male and female) and site (Chizé and Trois Fontaines) are defined by points of different colors and shapes. The stress has a value of 0.14 . 


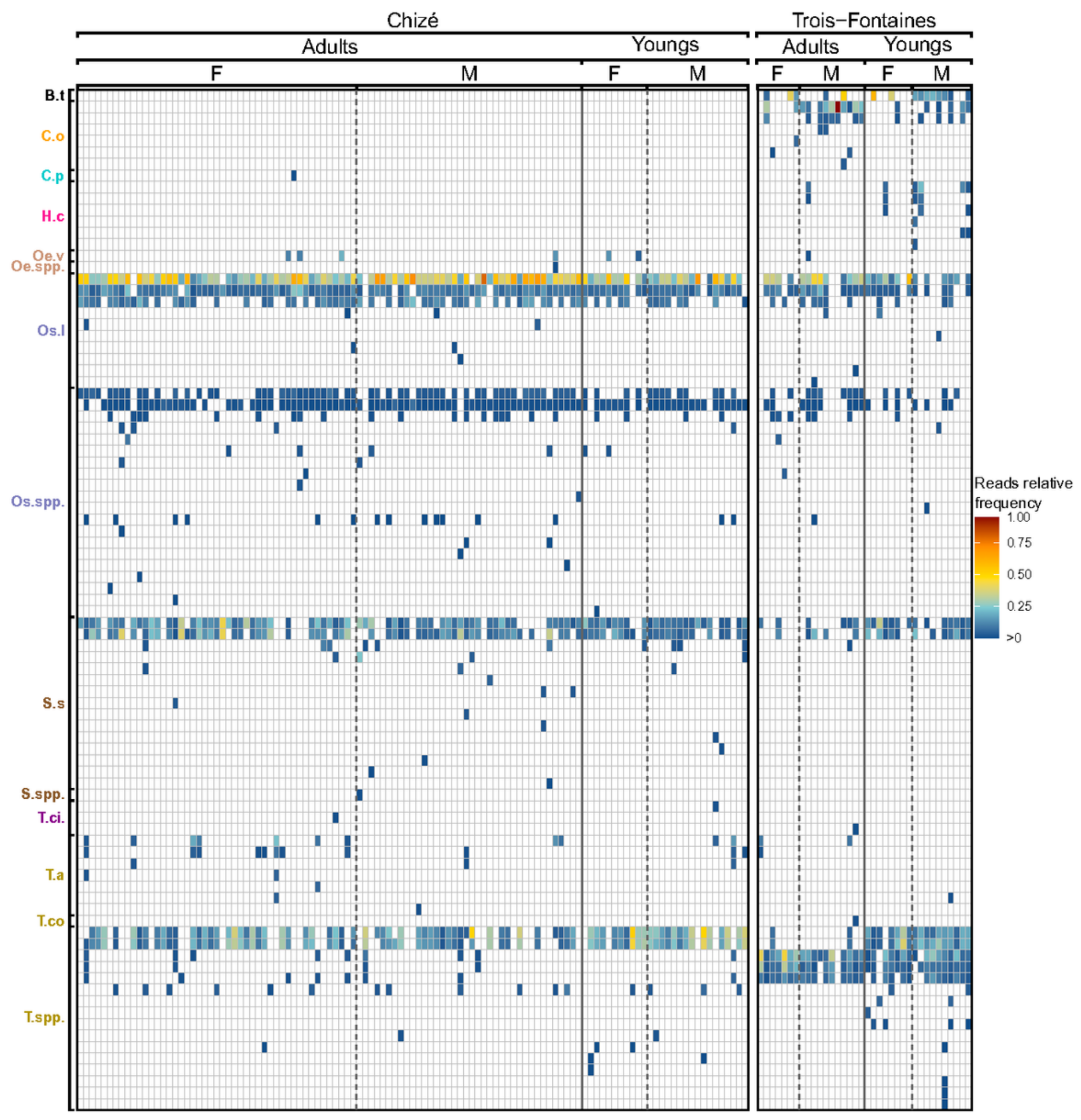

Figure 5

Heatmap of ASVs in samples. Each column corresponds to one sample of roe deer. Each row corresponds to a ASV with their assignment (B.t=Bunostomum trigonocephalum; $\mathrm{C} .0=$ Chabertia ovina; C. $p=$ Cooperia punctata; H.c= Haemoncus contortus; Oe.v=Oeusophagostomum venulosum; Os.I=Ostertagia leptospicularis; $\mathbf{S} . \mathbf{S}=$ Spiculopteragia spiculoptera; $\mathrm{T} . c \mathrm{i}=$ Teladorsagia circxumcincta: T.a=Trichostrongylus axei; T.co=Trichostrongylus colubriformis). ASVs names have the same color when 
they belong to the same genus. The data were split based on site location (Chizé or Trois Fontaines), age (young or adult roe deer) and sex (F: female and M: male). For each sample, the color indicates the read relative frequency of each ASV. Empty cells (white color) correspond to 0 reads at the end of the data curation.

\section{Supplementary Files}

This is a list of supplementary files associated with this preprint. Click to download.

- Supplementarymaterialvv4.docx

- graphicalabstract.png 